\title{
RITUAIS, FESTAS E LIRA CACERENSE: Iniciativas de implantação da escola primária republicana na fronteira Brasil Bolívia
} (1910-1913)

\begin{abstract}
Maria do Carmo Brazil
Adriane Cristine Silva1

Universidade Federal da Grande Dourados

RESUMO

O tempo da inauguração da República brasileira (1889) foi também o tempo da invenção da escola primária pautada nos princípios e projetos do novo regime. Os espaços escolares deviam ser organizados e animados, por meio do agenciamento urbano e da edificação, como símbolos dos novos valores educacionais incorporados doravante pela sociedade moderna. O objetivo desta abordagem foi discutir as dimensões históricas da escola primária instalada num dos rincões do oeste do país, mais precisamente a sudoeste do Estado de Mato Grosso. Erguida com seus vastos pátios e guarnecida de suas alfaias e paramentos essa escola representava o palco para a expressão do imaginário social e locus da ação política da Republica em sua magnífica pompa litúrgica. Com esse caráter a instituição lograva visibilidade social e, ao mesmo tempo, ajudava a revigorar princípios culturais vivenciados pela sociedade. O recorte temporal envolveu o período compreendido entre 1910-1913, primeiros anos do processo de surgimento do Grupo Escolar Espiridião Marques, implantado na cidade de Cáceres, MT (fronteira Brasil-Bolívia), com destaque analítico para as relações sociais aquilatadas pela civilidade, civismo e outras devoções do interesse público. Nesta reflexão os rituais e festas foram tomados como parte do "sistema simbólico" que à luz do referencial de Pierre Félix Bourdieu (1989), cumpre a função política de legitimar ou garantir as relações de poder. Recorremos às informações contidas, sobretudo, no Jornal a "Razão" e no Jornal "Argos", ambos de circulação local, fontes de onde emergem algumas representações da difusão das ações da Republica em Matos Grosso, impressos em suas dimensões simbólicas e pedagógicas.

Palavras-chave: Cultura material, festas cívicas, Mato Grosso.
\end{abstract}

\section{RITUALS, FESTIVALS AND LIRA CACERENSE: Initiatives deployment Republican primary school in the Brazil Bolivia (1910-1913)}

\section{ABSTRACT}

The time of the beginning of the Brazilian Republic (1889) it was also time for the invention of the school based on the principles and designs of the new regime. The school premises would be organized and animated by the agency and the city building, as symbols of the new educational values embodied now by modern society. The goal of this approach was to discuss the historical dimensions of the school housed in a hidden corner of the west of the country, specifically the southwestern state of Mato Grosso. Built on its vast courtyards and lined with their vestments and the school represented the stage for the expression of social imagination and the locus of political action of the Republic in its magnificent liturgical pomp. With this character the institution duped social visibility and at the same time, helped to reinvigorate cultural principles experienced by society. The time frame involved the period 1910-1913, the early years of the process of emergence of the primary school Espiridião Marques, deployed in the city of Cáceres, Mato Grosso (Brazil-Bolivia border), especially for analytical value by social civility, civism and other devotions of the public interest. In this reflection of rituals and festivals were taken as part of the "symbolic system" that in reference of the Felix Pierre Bourdieu (1989), meets the 
political function of legitimizing or guarantee the power relations. We inquired the information contained especially in the newspapers "Reason" and "Argos", both locally published, with sources emerging from some representations of the actions of the dissemination of the Republic in Mato Grosso, printed in their symbolic and pedagogical dimensions.

Keywords: Material culture, civic festivals, State of Mato Grosso.

\section{O cenário social}

A localidade de São Luiz de Cáceres, ${ }^{2}$ surgiu em 6 de outubro de 1778, portanto durante o período colonial no sertão mato-grossense, por iniciativa da política colonial portuguesa de ocupação, sob comando de Luiz de Albuquerque de Mello Pereira e Cáceres, quarto Capitão General de Mato Grosso.

Essa antiga cidade, ergueu-se a sudoeste do Estado de Mato Grosso, na margem esquerda do Paraguai, rio de extrema importância histórica para a região. Surgiu sobre um terreno plano e arenoso, cujas ruas foram cortadas em ângulos retos, onde se assentaram casas, em sua maioria, térreas. Segundo o censo realizado no ano de 2010, a cidade conta hoje com 87.912 habitantes. Limita-se com os municípios de Barra dos Bugres, Poconé, Corumbá, Livramento, Mato Grosso, Mirassol D’Oeste e República de Bolívia (Figura 1).

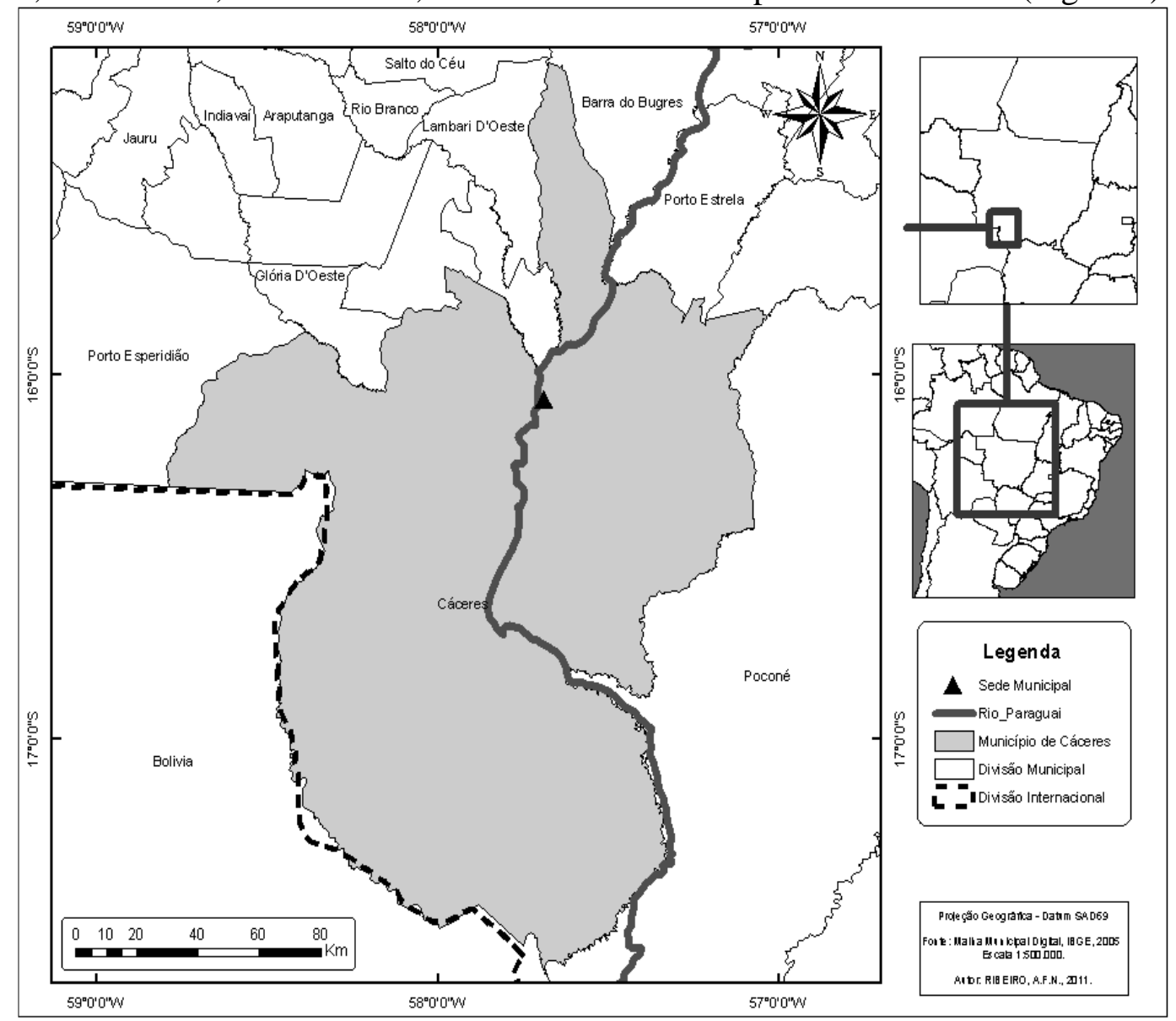

FIGURA 1. Localização da cidade de São Luiz de Cáceres. Figura delineada em mapa com divisão político-administrativa. Fonte: Ribeiro (2011), da dissertação Grupo Escolar Esperidião Marques Uma contribuição para os Estudos Das Instituições Escolares em Mato Grosso 1910-1947. 
Caracterizou-se pela formação de antigas fazendas pastoris que contribuíram para o seu desenvolvimento e composição de sua história. Grande parte dos produtos econômicos de Mato Grosso saía do porto de Cáceres e era escoada para os países platinos através do Rio Paraguai. Foi no cenário urbano de Cáceres que se assentaram, já nas primeiras décadas do século 20, as primeiras estruturas organizacionais do Grupo Escolar Esperidião Marques, inserido no campo da História das Instituições Escolares. Surgiu em 4 de fevereiro de 1910 como importante instituição escolar de Mato Grosso, alcançado pelo projeto republicano de ensino. O professor Venâncio José da Silva foi um de seus fundadores, o qual passou a direção da escola ao professor José Rizzo, e de acordo com o escritor Natalino Ferreira Mendes (1973), este passou a exercer o cargo de inspetor escolar, vindo a organizar aquela Instituição de Ensino nos moldes de outros Estados do país.

\section{A institucionalização da escola primária em Mato Grosso}

A institucionalização da escola primária foi centrada nos ideais republicanos de modernização e à esteira deste princípio as escolas foram juntadas num sistema amplo da Instrução Pública, "cuja estrutura organizacional tinha no topo da pirâmide os presidentes de Estado, seguidos dos Diretores Gerais, da Inspetoria, dos Diretores das escolas e, por fim, dos professores e alunos" (REIS, 2006, p. 208).

Este novo modelo de escola, oriundo do projeto paulista de escola, criado em 1893, e implantado em 1894, emergiu no Rio de Janeiro em 1897, e se espalhou no Brasil, alcançando efetivamente Mato Grosso em 1910, proporcionando novos rumos no sistema educacional de Mato Grosso. Nos moldes de educação estatal, representado pelos grupos escolares " $[\ldots]$ surgiu primeiramente com a tarefa de garantir - por meio do ensino - que a população em seu conjunto fosse homogeneizada, e, para tanto, o conhecimento das primeiras letras e das noções de coisas era requisito básico" (REIS, 2006, p. 202).

Pedro Celestino Corrêa da Costa, quatro dias após assumir o Governo do Estado de Mato Grosso em 12 de outubro de 1908, apresentou um extenso programa de governo. Um dos objetivos do referido programa era industrializar o estado, oferecendo-lhe infraestrutura necessária, mas para tanto, era preciso primeiro modernizar o sistema escolar. Sua mensagem enviada à Assembleia Legislativa de Mato Grosso, datada de 13 de maio de 1910, evidenciava o claro propósito de inserir Mato Grosso no projeto nacional republicano de modernização. Pedro Celestino entendia que o primeiro passo devia ser a habilitação do pessoal docente: nenhuma reforma eficaz é possível na instrução primária sem a conveniente habilitação de pessoal para a regência das escolas dessa categoria, e sem o mais que se reger para a proficuidade delas (MENSAGEM, 1910).

Pedro Celestino tinha a convicção de que o projeto nacional de escolarização do ensino primário era viável, ao mesmo tempo em que apontava as necessidades e os limites relativos à educação de Mato Grosso: suas palavras anunciavam o emprego de esforços necessários para alcançar essa meta - "Está o governo aparelhado para melhorar a parte material da instrução, proporcionando-lhe todos os recursos necessários, mas faltam-lhe bons professores para todas as localidades, como é para desejar" (MENSAGEM, 1910).

Uma saída para seus objetivos estava na formação dos jovens ao longo do tempo: '[...] e isso só se conseguirá [...] preparando moços para o magistério público que deve tornar-se atraente e de real proveito para a sociedade' ( MATO GROSSO, 1910, p. 7).

Desta forma, inaugurava-se um novo momento no sistema escolar do estado, materializado nos grupos escolares, criados oficialmente em Mato Grosso desde 1908, pela 
Lei $n^{\circ}$ 50. Esta Lei representava o gérmen inovador da Reforma da Instrução Pública Primária de 1910. Mas foi, segundo Cestari, o Regulamento para a Instrução Primária de Mato Grosso, expedido por meio do Decreto $\mathrm{n}^{\circ} 265$ de 22 de outubro do mesmo ano, a ser observado a partir de 1911, que estabeleceu novos critérios.

[...] O ensino primário deveria ser leigo, gratuito, ministrado à custa dos cofres estaduais, a todos os indivíduos, de ambos os sexos, sem distinção de classes nem de origem (Art. $1^{\circ}$ ); as escolas primárias seriam criadas em todas as cidades, vilas e povoados do Estado, que tivessem 25 meninos nas condições para frequentar a escola (Art. $2^{\circ}$ ); a obrigatoriedade do ensino para crianças de sete aos 10 anos de idade (Art. $5^{\circ}$ ); a obrigação da escola primária restringir-se-ia aos meninos residentes dentro do circulo traçado pelo raio de um quilometro médio da sede da escola (Art. $9^{\circ}$ ); as escolas se dividiriam em escolas do sexo masculino, regidas de preferência por professores e escolas do sexo feminino, regidas por professoras; poderiam também ter nas pequenas freguesias e povoações, escolas mistas regidas, de preferência, por professoras (Art. 10) e nenhuma escola primária poderia ter mais de setenta alunos matriculados (MATO GROSSO, 1910, Art. 16).

O Regulamento de 1910 permitiu a criação de Grupos Escolares (GEs) nas cidades mais prósperas de Mato Grosso, pois os recursos eram insuficientes para atender as demais localidades. Conforme o Álbum Gráfico do Estado de Mato Grosso (1914), entre os anos de 1893-1913 havia receita nos cofres públicos, mas não suficientes para atingir os objetivos almejados pela Direção Geral da Instrução de Mato Grosso. No entanto, ficou assegurada a instalação dos referidos grupos nas diversas localidades de Mato Grosso até o ano de 1930.

Mas, no período de 1910 e 1912, verificou-se a fase mais expressiva de criação de Grupos Escolares em Mato Grosso. Dos oito (GEs) instalados no Antigo Estado de Mato Grosso, dois situavam-se na região do atual Estado de Mato Grosso do Sul, conforme observa-se no Quadro 1. Grupos Escolares em Mato Grosso 1910-1912.

QUADRO 1. Grupos Escolares em Mato Grosso 1910-1912.

\begin{tabular}{|l|l|l|}
\hline \multicolumn{1}{|c|}{ Nome } & \multicolumn{1}{c|}{ Cidade } & \multicolumn{1}{c|}{ Ano } \\
\hline Escola Modelo Barão de Melgaço & Cuiabá $-1^{\circ}$ Distrito & 1910 \\
\hline Grupo Escolar Senador Azeredo & Cuiabá $-1^{\circ}$ Distrito & 1910 \\
\hline Grupo Escolar Dom Pedro II & Cuiabá $-2^{\circ}$ Distrito & 1912 \\
\hline Grupo Escolar General Caetano de Albuquerque & Poconé & 1912 \\
\hline Grupo Escolar Presidente Marques & Rosário do Oeste & 1912 \\
\hline Grupo Escolar Esperidião Marques & São Luiz de Cáceres & 1912 \\
\hline Grupo Escolar Luiz de Albuquerque & Corumbá & 1912 \\
\hline Grupo Escolar Dr. Joaquim Murtinho & Campo Grande & 1912 \\
\hline
\end{tabular}

Fonte: Arquivo Público de Mato Grosso (2010).

Os grupos escolares foram alguns dos expoentes do republicanismo, dentro de um dos seus pilares - a modernização. À esteira do modelo educacional republicano de organização da escola primária, criado inicialmente no Estado de São Paulo, outras unidades federativas, como Mato Grosso, por exemplo, também procuraram erguer seus templos de civilização visando à universalização da educação, traduzido regionalmente na 
reforma Pedro Celestino de 1910. (Souza 2006, p. 35). No âmbito Reforma da Instrução Pública Primária de 1910, emergiu no ano de 1912, entre outras instituições, o Grupo Escolar Costa Marques, cuja toponímia evoluiu para Esperidião Marques.

\section{Na boca da imprensa}

Dois periódicos foram utilizados como fonte para a presente reflexão: o Jornal "A Razão" e o Jornal "Argos" de circulação local, disponíveis em micro-filmes do acervo do Arquivo Público do Estado de Mato Grosso. Eram publicações periódicas de importância indiscutível para a população local e, transformaram-se em material de pesquisa de valor inestimável para o campo da história e da história da educação. Segundo o pesquisador português António Nóvoa (1997, p.11) "é através da media que se manifestam a maior parte das "vozes", dos projectos, dos anseios e das realidades dos diversos actores".

Embora inúmeros historiadores tenham tecido significativas considerações acerca do uso do jornal como principal fonte de informação histórica, José Honório Rodrigues na obra "Teoria da História" (1957) ponderou ela deve ser tomada com parcimônia, pois nem sempre são independentes e exatas; ou seja, muitas vezes, ela esconde uma intenção, implícita ou explicita. A esse respeito também advertiu Jean Glenisson (1991), em sua obra "Iniciação aos Estudos Históricos" sobre a dificuldade de se saber o nível de influências ocultas apresentadas ao público leitor por meio de imprensa, especificamente no que diz respeito à publicidade e à pressão exercida pelo governo sobre esse meio de comunicação.

Segundo Carla Pinsky (2005), embora a utilização da imprensa como fonte de investigação imponha cautela e rigor científico, conforme bem destacaram Rodrigues e Glenisson, esse instrumento só ganhou a atenção dos estudiosos, a partir da década de 1970. Até então, como no resto do mundo ocidental, a escrita da história do Brasil, por meio da imprensa, tinha pouca relevância, considerando a depreciação das fontes não tradicionais. Ou seja, Segundo Pinsky, havia a tendência de imaginar que a "verdadeira" narrativa dos fatos só podia ser realizada por meio de documentos oficiais, vistos como marca ou sinal de "objetividade, neutralidade e fidedignidade".

Como contraponto a essa tendência, desenvolveu-se nessa mesma década um proveitoso debate que veio contribuir para o avanço da produção historiográfica. As fontes jornalísticas passaram a ser tomadas como objeto de debate. Destacou-se nesse cenário o trabalho de do historiador Arnaldo Contier (1970), traduzida no livro "Imprensa e ideologia em São Paulo" (1979), resultante de sua tese de doutorado. A partir daí, Segundo Gressler (2010, p.53) os movimentos sociais emergentes, sobretudo das cidades, passaram a ser estudados através dos jornais, enquanto instrumento essencial de arregimentação e politização da época.

Feitas as considerações concernentes ao papel da imprensa como fonte de pesquisa, recorremos às informações que circularam através dos jornais cacerenses, levando em conta a época em que o material foi produzido, considerando, sobretudo sua vinculação política como é o caso do "Jornal A Razão", instalado em Cáceres em 17 de maio de 1917, destinado ao órgão do partido republicano mato-grossense, sob a direção do professor Demétrio Costa Pereira de (1917-1939) e do Dr. Leopoldo Ambrosio Filho, de 1939 até 1954.

Outro arquivo jornalístico consultado refere-se ao "Argos", jornal que circulou em Cáceres de 1911 a 1914. Este jornal foi fundado por Generoso Pereira Leite e tinha como colaboradores, dentre outros, Pedro Trouy, general Aníbal da Mota, Demétrio da Costa Pereira e João de Campos Widal. Desse material selecionamos alguns artigos, manchetes, 
propagandas e editoriais, os quais foram lidos e transcritos, para posteriormente ser analisado o cotidiano da escola e da cidade cacerense. A partir daí, entrelaçamos os dados que nos permitiram perceber parte do cotidiano escolar, o detalhamento da obra do Grupo Escolar Esperidião Marques (GEEM) e de seus atores sociais.

\section{O GEEM e a materialização do projeto republicano}

Definida oficialmente a criação do Grupo Escolar de São Luiz de Cáceres - pelo Decreto do Poder Executivo de 1912, cujo gérmen foi a Reforma da Instrução Pública Primária de 1910, erigiu-se assim uma escola ancorada nos preceitos do positivismo, nacionalismo, liberalismo e laicismo, a qual ganhou significado especial para a sociedade cacerense. Desde então a instituição serviria de instrumento difusor do ideário de modernização e de progresso proposto pelo regime republicano, inaugurado em 1889.

No que se refere ao impacto da valorização da escola para a sociedade, a historiadora Circe Bittencourt faz o seguinte destaque:

As tradições nacionais e o ritual das festas cívicas", escrito em 1988 e publicado em 1990, que o regime republicano, ao privar o direito de voto aos não alfabetizados, colocou o ensino em posição privilegiada, sobretudo em relação à constituição do direito político dos cidadãos brasileiros: "Ser cidadão, com determinados direitos [...] significava também cumprir obrigações e estar de acordo com valores ditados pelo poder constituído, sendo que estas normas estabelecidas integravam uma das aprendizagens fundamentais para o aluno. (BITENCOURT, 1990, p. 165).

As dimensões históricas da escola, da cidade e dos direitos envolveram a localização (fronteira Brasil-Bolívia), e, sobretudo suas formas de representação municipal e de relações sociais aquilatadas por um regime pautado na cidadania, civilidade, civismo, higienização, progresso. Nestes quesitos a elite política e econômica da cidade tratou de se mobilizar para levar a efeito o projeto de modernização, a partir do ensino. Com base nesse propósito, ao raiar o ano de 1913, o Coronel José Dulce, rico morador local, vinculado ao comércio platino por meio da Empresa Dulce \& Cia, doou ao Governo do Estado um terreno para a construção de um edifício próprio, onde mais tarde iria funcionar o Grupo Escolar. Estava explícita para a sociedade cacerense a valiosa contribuição do "ilustre cidadão" cacerense na conquista da propalada modernização.

Em noticiário publicado em 27 de abril de 1913, o jornal "Argos" - da imprensa cacerense - prestava preciosas informações aos leitores acerca da importância política da procissão cívica ocorrida na cidade de Cáceres. Vale lembrar que tanto as festas cívicas como os eventos de encerramento ou exposições escolares promovidas pelas instituições públicas traduziram-se, conforme observou Rosa Fátima Souza, como um dos os traços manifestos da aliança da escola primária com o regime republicano, acompanhado dos valores cívico-patrióticos (SOUZA, 1998, p. 265):

Tais festas tinham como objetivo solenizar algumas datas "notáveis" da nossa história, como se referia o diretor da Escola Normal, Gabriel Prestes, em relatório de 1895, citado anteriormente. Nesse ano, ele deu ciência à Inspetoria do Ensino da realização de cinco festas: "essas solenidades infantis, que interessam vivamente o espírito público, fazendo afluir à Escola uma enorme concorrência de espectadores, 
realizaram-se nos dias 21 de Abril, 13 de Maio, 8 de Junho, 29 de Novembro e 7 de Dezembro (Rel., 1896c).

Segundo o editorial de Jornal "Argos", o dia 21 de abril, data que trazia à memória o martírio de Tiradentes, foi escolhido para ser realizado o agradecimento público ao benfeitor da cidade (Coronel José Dulce). Uma imponente festa foi organizada pela Direção do Grupo Escolar "Costa Marques" e seu corpo docente. Nessas solenidades era comum a homenagem a algum representante da República, inauguração de salas, entrega de estandartes, torneios de ginásticas, discursos, entre outros.

Também era praxe o culto às datas cívicas, como parte "dos dispositivos regimentares, segundo os quais, na véspera dos dias de festa nacional, cada professor faria no último quarto de hora preleção a respeito da data que iria comemorar". Souza (1998, p.241), lembra que ao transformar as datas cívicas em atividade escolar, o Estado fazia do espaço escolar um instrumento de lembrança e de memória histórica, no sentido de legitimar o novo regime. Lembra ainda a autora que na obra "A formação das almas", Carvalho (1990) explica que o conjunto de mitos surgidos nos albores da República, como o mito do herói nacional e os símbolos nacionais eram empregados no sentido de redefinir as novas identidades coletivas:

Em realidade, ao instituir uma nova ordem política, a República reatualizou problemas latentes na sociedade brasileira, tais como: as questões da identidade e da unidade nacional. A transição do Império para a República representou momentos de crises e tensões sociais com grande perigo de desagregação. Era preciso, pois, construir um novo universo simbólico, uma vez que, como assinala Carvalho, a Proclamação da República fora um movimento de poucas raízes populares que precisava de legitimação. $\mathrm{O}$ forte apelo aos valores cívicos e o culto aos símbolos nacionais aparecem, portanto, como uma forma de se restabelecer a unidade e a integração social ameaçada. (SOUZA,1998,P.265)

Circe Bittencourt (1997) corrobora essa ideia ao afirmar que nos primeiros anos da República essas atividades eram programadas pela escola oficial, considerando as comemorações relacionadas às datas nacionais, "de rituais para hasteamento da bandeira nacional e hinos pátrios, além de uma série de outras festividades [...] sob o título de cívicas". Estas festas realizadas, sobretudo, o advento da República, compunham-se com as demais disciplinas o cotidiano escolar.

Bittencourt (1997) lembra ainda que, as autoridades educacionais organizavam e fiscalizavam rigidamente essas práticas escolares, as quais deviam ser também acompanhadas por leituras que traziam valores e princípios da "unidade nacional", a despeito da carência de livros didáticos adequados ao ensino das disciplinas direcionadas às novas exigências do mundo dito moderno.

Ao destacar itinerário e saudações, a matéria estampada no frontispício do Jornal "A Razão", datada de 27 de abril de 1913, conferia conhecimento das ruas por onde desfilou o cortejo ocorrido naquele dia de comemorações (21 de abril): "Assim constituída a procissão cívica, pôs se ela a caminho, tendo realizado seu percurso pelas ruas Augusta, General Osório, General Antonio Maria, Praça Major João Carlos, Ruas Padre Cassemiro, 13 de junho, Praça Barão do Rio Branco, Rua Coronel Faria, e novamente Rua Augusta" (JORNAL A RAZÃO, 1913). Entre os partícipes do evento foram feitos os seguintes saudações em destaque: 
Ao Coronel José da Costa Garcia, Intendente Geral do Município, e Major Luiz da Costa Garcia, Juiz de Direito interino da comarca pelo esforçado aluno Luiz de Moraes Botelho, filho do Major José J. de Moraes Botelho. Ao venerando General Antonio Anníbal da Motta, veterano da campanha do Paraguay e atual presidente da Câmara Municipal, pela grácil menina Esther Viegas, filha do Major João Viegas Muniz. A redação desta folha pelo colegial José Antonio Pinto Guedes, filho do Capitão Francisco Pinto Guedes. Ao Sr. Coronel Diogo Nunes de Souza, deputado Estadual, pelo aluno Antonio Bastos, filha da exmª. D. Anna Josepha R. Bastos. Ao Sr. Capitão Demetrio Costa Pereira, antigo professor e Inspetor Escolar desta cidade, pelo escolar José Rodrigues Fontes, filho do Capitão Rodrigues Fontes. Ao vice cônsul francês Sr. Lênin Reynier pelo pequeno Genésio de Arruda, filho do Capitão Francisco Pinto de Arruda. Aos comandantes dos corpos desta guarnição, Srs. Capitães José da Fonseca Moraes, do $38^{\circ}$ Batalhão Vicente A. Mangabeira, do $5^{\circ}$ de engenharia, pelo talentoso aluno Luiz de Albuquerque Nunes, filho do Capitão João de Albuquerque Nunes. E, finalmente, ao Sr. Coronel José Dulce, em prova de reconhecimento pela oferta por ele feita ao governo do estado de um terreno para a construção de um edifício próprio, onde possa funcionar o grupo escolar, pela simpática colegial Constança de Miranda, neta do Exmº ${ }^{\circ}$ Dr. Constança de Miranda (JORNAL A RAZÃO, 1913).

Observe-se que o evento chamava a atenção popular por seu caráter formal, feérico e atos de protestos de veneração e respeito pelas autoridades locais. Do preito emanava o sentido educador da escola perante a sociedade, sobretudo na prelação da direção da escola ou no momento do desfile do batalhão infantil ao prestar continência às autoridades locais. Nestes desfiles estudantis, apresentações de ginastas e demais comemorações, lembra Jorge Nagle (1996), representavam uma extensão adicional realizada pela escola, no sentido de interar, por meio das práticas pedagógicas, os valores e princípios da "unidade nacional" impingidos nos desígnios educacionais.

\section{Rituais, festas e "lyra" cacerense: dimensões simbólicas da escola}

Uma espécie de parada escolar teve início naquela manhã de 21 de setembro de 1913, formada na rua, em frente ao grupo escolar, onde foi realizada em extenso cortejo. Os detalhes da festa foram narrados pela imprensa local, representada pelo Jornal "Argos", com detalhes para o préstito escolar (Jornal Argos, 28 de setembro de 1913).

"PRESTITO: Às 8 horas da manhã formou-se, na rua, em frente ao grupo escolar, o extenso cortejo. Seguiam na frente 58 alunas, trajadas de branco com uma faixa auri-verde, a tira-colo, empunhando muitos explendidos bouques de flores naturais. Iam de duas em duas, e em seguida marchavam uma longa coluna de 78 alunos, também uniformizados de branco e com auriverdes distintivos ao peito esquerdo. Ao lado das filas caminhava o corpo docente e após vinha o sr. Diretor do Grupo acompanhado do capitão João Rosa de Lima e sargento do 38 Batalhão Orivaldo Caldas, instrutores musicais e militar dos alunos. Fechava o préstito a banda musical Lyra Cacerense, sob a regência do maestro José Fernandes da Silva.(JORNAL ARGOS, 1913). 
Rosa Fátima de Souza (1998, p.272) salienta que Roberto Da Matta (1990) via as vestimentas como extensões do corpo e implicavam em determinados gestos e comportamentos. Além disso, para Da Matta o uniforme era como uma poderosa capacidade de igualar todos os indivíduos num mesmo nível de posição. Ancorada nessas observações de Da Matta, Souza salienta que a farda, não obstante, possuía outros simbolismos:

(...) além de igualar, ela corporifica, simboliza poder e ordem. Como afirma o autor : 'seu uso é coerente com a ordem cotidiana e seu formalismo é criado pela consciência aguda da ordem. As fardas simbolizam identidades sociais concretas e que operam em todos os níveis da vida social' (Da Matta, 1990, p.51). Talvez isso explique o encantamento que os batalhões infantis produziam nos alunos, nos professores e na sociedade. Ao marcharem pelas ruas da cidade - e, na marcha há também um componente de uniformização de gestos e continência gestual (ibidem, p.51) -, o batalhão oferecia a representação de um corpo unido e harmônico, como deveria ser a pátria e a nova ordem. A versão da escola-quartel, o ideal disciplinar da escola republicana, permaneceu nas escolas públicas do Estado de São Paulo. $\mathrm{Na}$ década de 1920, os batalhões infantis foram substituídos pelo escotismo e pelas linhas de tiro. A militarização da infância havia de perdurar muitas décadas ainda”. (SOUZA, 1998, p.272).

A banda musical "Lyra Cacerense" executava diferentes peças do seu repertório, e aos poucos a grande varanda, artisticamente ornada, que ia servir de salão de honram apinhava-se de convivas e demais membros da comunidade escolar. A riqueza de detalhes trazida pelo editorial do jornal impressiona o leitor:

Os assentos foram todos tomados, misturando-se as cores vivas das toilletes elegantes com os tons sombrios das graves sobrecasacas pretas. Lá fora pompeava um sol de fogo, produzindo, ali naquele ambiente, uma temperatura senegalesca, que punha em continua atividade a bateria de leques e ventarolas. Os salões e mais dependências do vasto prédio em que funciona o referido estabelecimento de ensino, regurgitavam de convidados, senhoras, senhoritas e cavalheiros da nossa melhor sociedade, além da numerosa concorrência de alunas e alunos, trajando a capricho para assistirem aquela solenidade. (JORNAL ARGOS, 1913).

Jovens e crianças improvisavam discursos causando excelentes impressões ao público, participante do cortejo escolar, o qual foi disperso logo depois da fala de José Rizzo, Diretor do Grupo Escolar. O editorial trazia também a relação dos docentes da instituição, com alguns destaques, a saber:

(...) professoras exmas. D. Rita Marques Garcia, do $1^{\circ}$ ano da sessão feminina; Anna M. Xavier do Vale, do $2^{\circ}$; Esmeraldina Malhado, do $3^{\circ}$; bem como a senhorita Antonia H. Garcia, que dirige o $1^{\circ}$ ano da sessão masculina, e os professores os Srs. Eduardo Malhado, do $2^{\circ}$ ano Capitão Antonio Correa do Couto, do $3^{\circ}$ ano o tenente coronel Pedro Breny, do $4^{\circ}$ ano. (JORNAL ARGOS, 1913). 
$\mathrm{Na}$ ocasião foi realçada a falta de um estandarte do Grupo, que poderia ser traduzida "numa pequena e artística bandeira nacional para o batalhão infantil". Para suprir a lacuna foi lembrado o trabalho das moças cacerenses que se empenharam na confecção de um estandarte de seda, destinado a "irmandande da Perseverança", tradicional confraria da cidade.

Apropriando-nos do referencial de Eric Hobsbawm (1997), consideramos estas práticas rituais e simbólicas como conjunto da tradição inventada da escola primária no Brasil republicano, destinado não apenas, para regular comportamento apresentados diariamente por professores e alunos no interior das instituições escolares, como também impingir valores e normas sociais, sobretudo educacionais. Nesse processo de construção do imaginário republicano, a escola desempenhou papel essencial, pois coube a ela "formar almas", conforme salientou Souza, ao referir-se às reflexões de José Murilo de Carvalho (1990), com destaque para sua função na construção da identidade e da unidade da nação. Segundo Souza (1998, p.266), a atribuição da escola ia além da simples transmissão de uma cultura comum ou propagação de valores morais e cívicos. Ao contrário, ela alcançava o "nível do imaginário, dos sonhos, das aspirações, das esperanças e do inconsciente".

Segundo Vidal (2004, p. 142), os grupos escolares assumiram, "especialmente nas cinco primeiras décadas do século 20 , a posição de uma escola de verdade a uma parcela da sociedade brasileira, para qual funcionou como símbolo de coesão e status".

\section{Germes da Construção}

Cabe lembrar que na segunda metade do século 19, principalmente durante a transição do regime Imperial para o Republicano, a vinculação entre cidade e escola ainda permaneceu alimentada por perspectivas pouco promissoras. A dificuldade de acesso à escola, a escassez de instituições educacionais públicas e de professores habilitados para atuar na instrução primária sinalizavam a pouca chance de formar cidadãos. Sem a escola, lócus humano do diálogo, do contato, da organização, da troca e da transmissão dos valores cívicos e políticos, muitas cidades do interior brasileiro quase se confundiam com as formas construídas do campo, lugar que simbolizava ignorância, analfabetismo e atraso (COSTA, 1995, p. 277).

No âmbito de Mato Grosso, Gervásio Leite, na obra "Um século de Instrução Pública: História do Ensino Primário em Mato Grosso", publicada em 1970, infere que no tempo do Império, os relatórios e mensagens dos Presidentes eram repletos de registros acusando as carências materiais da Província. As condições deploráveis pelas quais passavam as antigas escolas régias refletiam no ânimo da sociedade que via com descrédito o nível de instrução pública.

Nesse sentido, os Grupos Escolares, organizados segundo um novo modelo de Escola, tinham a função conduzir a formação, a partir do ensino primário, conforme o ideário republicano, pautado na modernidade política. Esse ideário precisava alcançar os mais remotos recantos do país, pois se entendiam que os destinos da nação dependiam da qualidade de suas instituições, observando-se as interseções da dimensão política, social, econômica, jurídica, moral e psíquica da coesão social. A ideia era promover a transformação da sociedade brasileira a partir da escola primária, conforme observou Souza (1998) na seguinte passagem:

Tudo, então servia de arma para esta nobre campanha; lançava-se mão de todos os recursos para este fim. Exames públicos, exposições, certames literários e musicais, exercícios militares, torneios ginásticas, trabalhos 
manuais, jogos ao ar livre... em poucos anos, tornara-se desnecessária a propaganda da escola pública para atrair a população, mas as festas escolares haviam adquirido outros significados e respondiam a outras necessidades; elas tornaram-se momentos especiais na vida das escolas e das cidades, momentos de integração e de consagração de valores - o culto à pátria, à escola, à ordem social vigente, à moral e aos bons costumes. (SOUZA, 2998, p.259).

À esteira das observações de Souza acerca dos estabelecimentos de ensino paulista, o exame do material empírico referente à escola mato-grossense também revelou que desde as primeiras propostas de construção dos Grupos Escolares, apresentadas às principais instâncias do governo eram tratadas com prioridade pelos poderes constituídos locais e regionais. Esse aspecto evidencia-se numa matéria esboçada em 31 de agosto de 1913, quando o Jornal "A Razão" disponibilizou notícias sobre as primeiras propostas apresentadas à Secretaria dos Negócios de Agricultura e Obras Públicas, para a construção do Edifício do Grupo Escolar da cidade de São Luiz de Cáceres. A imprensa local em conjunto com o correspondente do periódico "Diário da Capital" fez o seguinte registro:

O Dr. João da Costa Marques [irmão do Governador], Secretário da Agricultura, de acordo com o parecer da junta de arrematação, resolvem autorizar o Sr. Dr. Diretor de Obras Públicas a lavrar contrato com o Sr. José Corbelino, para a construção do Grupo Escolar de São Luiz de Cáceres e cuja proposta no valor de $\$ 207.500 .000$, é a mais vantajosa para os interesses da Fazenda Estadual (Diário da Capital e Jornal A Razão, 1913).

A matéria informa que o Sr. José Corbelino havia solicitado aditamento a uma proposta anterior, mas acabou autorizando por telegrama seu procurador a fazer uma redução de 5\% sobre o valor da proposta, que ficou estimado em \$196.125.000, vencendo a licitação que envolveu outros dois proponentes - os Srs. Francisco Affonso Ramires que pediu \$219.000.000 - e Vilá S. Rueda com \$295.000.000.

Observa-se nos registros oficiais a dimensão do primado empenho político empreendido na concretização do projeto de construção do Grupo, pois isso significava o surgimento de mais um "templo de instrução". Esse mesmo destaque foi dado por Rosa Fátima de Souza ao referir-se à festa inaugural de um grupo escolar em Campinas no ano de 1910. O evento, conta a pesquisadora, foi realizado com brilhantismo envolvendo famílias, representantes de associações, dirigentes do Ginásio, comunidades da escola e de outras instituições do município, comissões de alunos munidos de seus estandartes, entre outros participantes. Da mesa de cerimônia fazia parte o diretor da escola, o inspetor escolar, Oscar Thompson, o diretor geral da Instrução Pública do Estado, prefeito municipal, representantes da Câmara e diretores do Ginásio e grupos escolares. Souza salienta que depois de entoado o hino A grande pátria pelos alunos, o diretor proferiu seu discurso de inauguração:

Campinas, essa princesa que se enganala de flores, estendendo-se no plácido e aveludado tapete de São Paulo ... rejubila-se de contentamento pela criação de mais um templo de instrução (grifos meus), onde a infância campineira alegre e sorridente vem, em constante peregrinação, receber a luz benéfica do saber que lhe dissipará da inteligência as trevas da ignorância ... Honrado com a distinção que me conferiu o governo do Estado de São Paulo, para diretor desse estabelecimento, depois de vinte 
longos anos de magistério, consagrados à causa da instrução! ... A vós meus dedicados colegas: a vós apóstolos da instrução, que assumistes o espinhoso encargo de educar essas esperançosas crianças dirijo um brado de animação, para que possais prosseguir com coragem por essa longa estrada cheia de espinhos, onde a glória os espera. (SOUZA, 1998, p. 260.)

No caso da cidade mato-grossense de Cáceres, a cerimônia de lançamento da pedra fundamental do edifício do Grupo Escolar Costa Marques foi noticiada por meio do editorial do Jornal "Argos" em 21 de setembro de 1913. O lançamento seria realizado no dia 24 de novembro do mesmo ano por deliberação do Governo do Estado, no qual foram nomeados como paraninfos a Senhora Anna Virginia Dulce, esposa do Coronel José Dulce, o Coronel Diogo Nunes de Souza, deputado da Assembleia Legislativa do Estado e José Rizzo, representante do Governo e diretor do referido Grupo.

Curioso destacar que o periódico lembrava aos leitores de que os convidados se reuniriam no edifício sito à Rua General Osório, onde funcionava a referida "Casa de Instrução", no dizer do editor. E seguiriam dali em préstito para a Praça Duque de Caxias, para realizar a aludida cerimônia.

Em matéria publicada em 28 de setembro de 1913, o mesmo Jornal dava conta dos detalhes do lançamento da pedra fundamental, cuja cerimônia teve início às 7 horas da manhã do dia 24 de setembro, em frente ao prédio provisório do Grupo, onde foi organizado um cortejo até a Praça Duque, local de realização do ato cívico.

\section{Uma festa cívica para o nascimento do Grupo}

Segundo as informações do Jornal "Argos", à frente do cortejo dirigia-se um grupo de alunos e alunas ao local da cerimônia. Todos de branco, de posse de diversos estandartes escolares, entre os quais brilhavam o auriverde da bandeira nacional. Acompanhando os alunos, estava um numeroso grupo de pessoas composto "de elegantes senhoritas, senhoras e cavalheiros", segundo expressão do editorial. A marcha durou dez minutos, alcançando o respectivo local que se encontrava "todo embandeirado, contendo diversos pavilhões para a recepção do público" (Jornal "Argos" 1913). Observe-se que esta era uma oportunidade para se promover ou exaltar a escola, com destaque para patrono e paraninfos.

O início da cerimônia foi marcado pela leitura do termo de pedido de lançamento da pedra fundamental, feito pelo secretário do Ato, Intendente Mario Motta. Na verdade, segundo o Regimento da Diretoria Geral da Instrução Pública de Cuiabá, fazia-se necessária a assinatura da Ata de Fundação ou de lançamento da pedra fundamental por parte de todos os presentes. O referido Regimento atendia aos ditames dos Ministérios de Instrução e do Fomento, cabendo ao primeiro a faculdade de dirigir, dar indicações, pugnar pelas condições escolares, autorizar remessa de material e mobiliário; e ao segundo, conceder a execução das construções, e empreitadas (Diário do Senado, 1913).

Isso explica a ênfase dada ao evento tanto pelas autoridades locais, como pelo Jornal "Argos" de 28 de setembro de 1913, acerca dos registros dos presentes que assinaram como testemunhas do Ato, com destaque o Diretor do Grupo Escolar José Rizzo - representante do Governo do Estado; Coronel Diogo Nunes de Souza; Exm. Dona Anna Virginia Dulce, paraninfos do ato: Coronel José da Costa Garcia, representante pessoal do Sr. Presidente do Estado; General Anníbal da Motta, presidente da Câmara Municipal e Coronel José Dulce, como doador do terreno onde mais tarde seria levantado o edifício. 
Autoridades civis e militares fizeram uso da palavra, como o paraninfo coronel Diogo Nunes de Souza; o advogado Clemente Barbosa, que leu um extenso discurso, e em seguida o Diretor do Grupo, cujo discurso estimulou aplausos dos presentes. Além das autoridades, Ester Viegas Muniz, aluna do $3^{\circ}$ ano, e José Pinto Guedes, aluno do $4^{\circ}$ ano, também pronunciaram eloquentes alocuções ao evento.

Iluminados pelo referencial de Pierre Bourdieu (1989), entendemos que toda a disposição dos objetos utilizados no Ato servia a um propósito, um sentido ou uma referência comunicante. $\mathrm{O}$ termo de lançamento, os cartões dos paraninfos, o telegrama do Governador - constituíam em instrumento claro utilizado para legitimação do poder. É assim que o segmento dominante de uma determinada sociedade garante sua legitimidade $\mathrm{e}$ ganha o "[...] poder de impor - e mesmo de inculcar - instrumentos de conhecimento e de expressão [...] arbitrários - embora ignorados como tais - da realidade social". (Bourdieu 1989 , p. 12). Um detalhe interessante ressaltado pelo Jornal refere-se ao ritual de lançamento da pedra:

Procedeu-se a tapagem da referida pedra. Com uma trolha de prata, expressamente mandada preparar pelo empreiteiro construtor Sr. Capitão José Corbelino, foram lançados pelos nomeados acima, as primeiras colheradas de argamassa nas juntas, e sobre elas colocado o competente tampo. Feito o que, por meio de aparelhos próprios, efetuou-se a sua colocação na escavação previamente feita (JORNAL ARGOS, 1913).

Observa-se nesse fragmento, a busca da consolidação das relações de poder sociais determinadas pelo poder material ou simbólico incorporado ou assimilado pelos agentes envolvidos na trama. Por trás dos pequenos objetos, como a trolha de prata, das "colheradas de argamassa", estava um mundo, um "poder quase mágico que permite o equivalente daquilo que é obtido pela força (física ou econômica), graças ao efeito específico de mobilização, que só se exerce se for reconhecido, quer dizer, ignorado como arbitrário" (BOURDIEU, 1989, p. 14).

Daí a presença da banda de música Estudantina executando o hino nacional, queimada de "girândolas de foguetes", a abundante mesa de café e bolos, champanhe e cervejas servidas aos convidados. Vale explicar que a banda de música Estudantina, constituía-se pelo agrupamento de músicos com número de componentes, cuja formação instrumental era variada e, em geral executava música popular brasileira, em meio a intelectuais e boêmios. Esse tipo de banda não se restringia ao universo cacerense. Inúmeras cidades brasileiras contavam com a presença de banda de música formada por instrumentos de sopro, de metal, aos quais se incorporam os saxofones e a bateria, cuja função era popularizar a música brasileira e, no caso das festas escolares ou datas comemorativas das cidades, estas bandas serviam para acompanhar os cortejos civis ou militares.

De volta ao evento de lançamento da pedra fundamental, cabe ainda ressaltar que o ritual simbólico foi concluído com felicitações ao Governador do Estado, Joaquim Augusto da Costa Marque e ao Capitão José Corbelino, considerando as proposições de Bourdieu (1989) de que os símbolos são produzidos para servir à classe dominante.

No caso particular do Grupo Escolar Esperidião Marques (GEEM), havia clara intenção política de instalar a instituição escolar em edifício próprio, erguida especificamente para fins de ensino primário no sentido de "preparar cidadãos para a sustentação, defesa e engrandecimento de uma pátria livre" (CARVALHO, 1989, p. 24). 


\section{O Grupo Esperidião Marques}

A construção do Grupo Escolar Esperidião Marques teve início no ano de 1913 e foi encerrada em 1920, na esquina da Praça Duque de Caxias, parte central da cidade. O prédio foi inaugurado em 9 de março do referido ano, mas só em junho de 1924 passou a designar-se Grupo Escolar Esperidião Marques.

Os prédios, além de cumprir a finalidade utilitária e funcional, deviam também imprimir sua dimensão social, simbolizar os novos valores a serem incorporados pela sociedade e traduzir a construção de uma nação moderna pautada na cultura e na educação.

Rosa Fátima de Souza (1998), assim refere-se ao caracterizar os primeiros grupos escolares do Estado de São Paulo, surgidos nos albores da República:

Estes edifícios puderam sintetizar todo o projeto político atribuído à educação popular: convencer, educar, dar-se a ver! O edifício escolar torna-se portador de uma identificação arquitetônica que o diferenciava dos demais edifícios públicos e civis ao mesmo tempo em que o identificava como um espaço próprio, lugar específico para as atividades de ensino e do trabalho docente. Na arquitetura escolar encontram-se inscritas, portanto dimensões simbólicas e pedagógicas (SOUZA, 1998, p. 123).

A escola, no início do regime republicano, tornou-se o símbolo da nova ordem, ou nas palavras da Marta Carvalho "o sinal da diferença que se pretendia instituir entre um passado de trevas, obscurantismo e opressão, e um futuro luminoso em que o saber e a cidadania se entrelaçariam trazendo o Progresso" (CARVALHO, 1989, p. 23).



FIGURA 2. Representação gráfica da fachada do GEEM, , com data de 1913, ano da inauguração do prédio. (Redesenhada por Antonio Carlos Vieira de Souza).

FONTE: Desenhos originais do acervo documental da Prefeitura Municipal de Cáceres.

No caso particular do Grupo Escolar Esperidião Marques (GEEM), havia clara intenção política de instalar a instituição escolar em edifício próprio, erguida especificamente para fins de ensino primário no sentido de "preparar cidadãos para a sustentação, defesa e engrandecimento de uma pátria livre" (CARVALHO, 1989, p. 24). 
No entanto, o prédio foi construído sem ter sido objeto prévio de planejamento urbano pelo fato de, conforme assinalado anteriormente, o terreno foi doado pelo comerciante José Dulce nos idos de 1912.

A construção da instituição ocorreu em espaço central da cidade, embora pouco distante da área comercial, sendo, portanto erguido em área valorizada de acordo com a configuração urbana da cidade, bem próximo à Rua Comandante Balduíno e Rua Tiradentes.

\section{Rendimento Escolar}

O modelo de ensino implantado pelos Grupos Escolares dispunha de inovações pedagógicas no que se refere ao aproveitamento. Os rendimentos "aprovados" ou "reprovados" imprimiam efeitos impressionantes entre alunos e pais de alunos, sobretudo quanto à rigidez no padrão de exigência.

No término de cada ano letivo, publicavam-se nos jornais os resultados obtidos pelos alunos, chamados na época de graus. Destacamos como exemplo, a lista das notas níveis de distinções obtidas pelos alunos nos exames finais do ano letivo de 1912 do Grupo Escolar Costa Marques (Quadros 9 e 10, p. 142).

QUADRO 2. $1^{\circ}$ ano A: Alunos da Sessão Masculina, regida pela adjunta interina Rita Marques Garcia

\begin{tabular}{|c|c|c|c|}
\hline Nome & Aprovação & Distinção & Grau \\
\hline João Ladislau de Carvalho & 6 & Plenamente & 5 \\
\hline João Candido Pinheiro Rego & “ & “" & 4,7 \\
\hline José Florentino Alves & “" & Simplesmente & 4 \\
\hline Catulino Paes de Arruda & “ & “" & 3,7 \\
\hline Heleodoro Vanini & “" & “" & 3 \\
\hline Pedro Arbus Torquato & “" & "“ & 3 \\
\hline Jose Jorge da Cunha & " & “" & 3 \\
\hline
\end{tabular}

Fonte: A Razão (1912). Organização: Silva (2010).

QUADRO 3. $1^{\circ}$ ano: Alunos da Sessão Feminina, regido pela adjunta interina Escolástica das Neves Botelho

\begin{tabular}{|l|c|c|c|}
\hline \multicolumn{1}{|c|}{ Nome } & Aprovação & Distinção & Grau \\
\hline Balbina Garcia & " & Plenamente & 5 \\
\hline Elzira Garcia de Arruda & " & " & 5 \\
\hline Teresa Fontes & " & " & 5 \\
\hline Clarice Fanaya & "“ & Simplesmente & 3,5 \\
\hline Brígida Benedita Leite & " “ & 3,5 \\
\hline Lucidia Avelina de Moraes & " & " & 3,3 \\
\hline Ana Rita de Oliveira & " & " & 3 \\
\hline Zulmira Barros & " & & 3 \\
\hline Paulina Enedina da Silva & & & \\
\hline
\end{tabular}

Fonte: A Razão (1912). Organização: Silva (2010).

Ao término de cada ano letivo, os resultados eram divulgados amplamente. A lista das notas obtidas pelos alunos do Grupo Escolar Costa Marques, sobretudo dos exames finais, publicava-se na imprensa local: "Amanhã, domingo, o Grupo Escolar desta cidade estará em festas para a distribuição de prêmios e diplomas aos seus alunos. As festas que serão públicas e realizar-se-ão às 9 horas do referido dia, não havendo convites". 
Comunicava-se a população da cidade das realizações do GEEM, demonstrando os resultados dos seus alunos à comunidade.

Por isso, a criança incorporada ao sistema escolar era continuamente submetida por mecanismos de controles institucionais, com destaque para matrícula, frequência, notas e condutas. Isso explica o motivo pelo qual muitas notas eram divulgadas com formalidade, apontando os primeiros classificados ou o rendimento defasado de outros. Um aspecto interessante refere-se ao fato de que muitas notas eram publicadas em jornais de circulação local. Em fragmento de um noticiário publicado anos mais tarde (1927) no Jornal A Razão evidencia o peso dos resultados dos exames do final do ano letivo:

Encerrou o ano letivo com uma modesta festa escolar, de conformidade com a praxe invariavelmente seguida no grupo escolar desde a sua fundação. Os alunos, e principalmente as alunas da casa porfiaram em manifestar seu regozijo, recitando e cantando poesias, cançonetas e hinos, obedecendo a um programa seleto e de muitos números. (JORNAL A RAZÃO, 1927).

A rigidez dos exames envolviam conteúdos das matérias lecionadas ao longo do ano, constituídas por provas práticas, orais e provas escritas (ditados e redações), sendo avaliadas as questões práticas de aritmética, caligrafia e desenho. Realizado os exames, realizava-se a classificação caracterizada em graus: distinção, aprovação plena, reprovação. Como coroamento dessa maratona realizada no âmbito do ensino primário, sobretudo no Grupo, ocorria a distribuição de prêmios e as festas de encerramento do ano letivo.

Foram distribuídos boletins de promoção, prêmios aos alunos aprovados com distinção (10) e diplomas aos que concluíram o curso preliminar (8), quatro de cada seção. A festa se designou de assistir os representantes dos Srs. Bispo Diocesano e intendente Geral, e os senhores Juiz de direito da comarca Comandante da Guarnição Federal e da Força Pública e outras autoridades civis e militares, famílias, cavalheiros e a petizada do estabelecimento e de fora. Realçou a festa uma orquestra de exímios amadores da arte de Carlos Gomes (JORNAL A RAZÃO, 1927).

Entendemos que uma estratégia utilizada pelos poderes constituídos, no sentido de atrair crianças e jovens para a escola, era a publicação evocativa nos jornais locais, no sentido de sensibilizar os pais para realizar as matrículas de seus filhos. As festas escolares além de causar o interesse público pela educação da infância estimulava a competição entre alunos, e mesmo emulação entre pais de alunos. Diante desse cenário, a inspetoria promoviam festividades solenes envolvendo a participação de autoridades, famílias, pessoas ilustres de localidade e cercanias.

\section{Considerações finais}

Seguindo as trilhas abertas pela pesquisadora Rosa Fátima de Souza em suas análises sobre a estrutura e a forma da escola primária criada no estado de São Paulo pelo projeto educacional republicano, com destaque para a instauração ritos, espetáculos, celebrações na escola primária republicana procuramos pensar as singularidades da escola mato-grossense, tomando o Grupo Escolar Esperidião Marques, como objeto de análise. Aos poucos a ambição tomou conta de nossos projetos e logo penetramos, como diria Marilena Camargo, no universo do "velho prédio escolar", que, além de divulgar a ação 
republicana, corporificou os símbolos, os valores e a pedagogia moral e cívica que lhe era própria.

Das análises acerca das características do Grupo Escolar Esperidião Marques, através de documentos, fotografias, plantas, edifício, foi possível inferir que a cultura material representou parte do processo de consolidação e divulgação dos valores republicanos o qual alcançou Mato Grosso, e mais especificamente Cáceres, espaço localizado no extremo oeste brasileiro.

Se refletirmos sobre o termo "cultura escolar" na perspectiva de Antonio Viñao, os limites de nossa abordagem ampliam-se ainda mais, pois para o referido pesquisador, cultura escolar não se limita apenas ao conjunto dos aspectos institucionalizados que caracteriza a escola como organização. Envolvem também "práticas e condutas, modos de vida, hábitos e ritos, a história cotidiana do fazer escolar - objetos materiais - função, uso, distribuição no espaço, materialidade física, simbologia, introdução, transformação (...) modos de pensar..." Viñao (1994, p. 68).

Dispondo de prédio próprio, diretor (gestor) e quadro docente permanente para atuar no ensino em séries iniciais, o GEEM desempenhou o papel indispensável para a difusão dos ideais da República. Para cumprir o projeto republicano, a escola adotava procedimentos básicos, alguns deles expressos em códigos de conduta que iam desde práticas diárias em sala de aula, passando por imputação de valores ligados ao amor à família, desprendimento, abnegação, dignidade pelo trabalho, e alcançavam exigências de posturas a serem incorporadas dentro e fora do âmbito escolar envolvendo disciplina, civismo, polidez, entre outros. Estes valores nacionalistas ao serem trabalhados dentro da escola traduziam-se nos cultos aos símbolos nacionais como hino, bandeira, brasões e cerimônias de homenagens aos vultos históricos brasileiros.

Festas, exposições escolares, desfiles, exames públicos e comemorações cívicas, lembra Souza, transformaram-se nos momentos especiais na vida da escola ou, por outra, "nas práticas simbólicas" que, no universo escolar traduziam o imaginário sociopolítico da nova forma de organização política do Estado.

Os exames públicos, as festas e exposições escolares e as comemorações cívicas explicitam as múltiplas formas pelas quais a escola primária construiu sua identidade institucional e estendeu sua pedagogia à sociedade mais ampla. Dimensão simbólica da cultura escolar, os rituais e espetáculos - momentos de dramatização do cotidiano -, estiveram implicados na construção da identidade institucional e desempenharam a função de sacralizar o grupo como uma expressão da pátria e da República. Essa pedagogia política e simbólica da escola primária não pode ser subestimada na compreensão da cultura brasileira na transição do século dezenove para o século vinte. (SOUZA, 1998, p277)

A despeito da visibilidade social, política e cultural alcançada com o advento da República, as práticas simbólicas desenvolvidas no âmbito institucional representam uma parte significativa da cultura escolar. Ao referir-se ao Grupo Escolar de Piracicaba, a autora ressalta que "as armas, os uniformes e o estandarte faziam parte da indumentária indispensável desses batalhões, símbolos de distinção e identidade".

Esse mesmo aspecto repercutia nos Grupos Escolares instalados nas áreas internas do Brasil. No caso do Grupo Escolar Esperidião Marques, erigido em Cáceres nos idos da década de 1910, as festas, as exposições escolares, os desfiles dos batalhões infantis, os exames e comemorações cívicas constituíram-se nos momentos especiais na vida dessa 
escola, razão pela qual ela ganhava ainda maior visibilidade social e reforçava sentidos culturais ali compartilhados (SOUZA, 1998, p.275).

No que se refere aos valores patrióticos, Souza com base no referencial dado por Raoul Girardet (1987), ajuda a explicar que a escola primária graduada além de conduzir sua missão pedagógica, ajudou na construção de um imaginário republicano provido de todos os signos animadores das consciências e das almas, como

[...] preleções, conferências, passeatas, demonstrações dos Batalhões Infantis, festas, solenidades. Por meio dessas manifestações cívicas, ela ajudou a instituir formas de falar e sentir sobre a pátria e a nação. A pátria consistia, pois, no símbolo da unidade da nação e a República foi considerada como a melhor forma de organizá-la tal como advogavam os positivistas. (SOUZA,1998, p.275).

Em suma, na escola, a Proclamação da República, a exaltação a Tiradentes, as datas históricas, a bandeira, o hino, os símbolos nacionais eram ensinados de acordo com a versão oficial. Mas significaram bem mais que simples lições de História. Em realidade, essa formação moral baseada no civismo republicano, tornou-se uma expressão do imaginário sociopolítico nas primeiras décadas da República.

Com essa perspectiva, tivemos a ambição de inserir nossas reflexões sobre do Grupo Escolar Esperidião Marques na corrente de esforços interpretativos que vem sendo realizado no campo da história da educação, no sentido de fazer avançar os estudos regionais acerca das instituições escolares. Procuramos discutir o GEEM, no contexto da historia nacional, mas considerando seu aspecto singular, como uma instituição localizada em área de fronteira (Brasil-Bolívia), contando com a participação de diferentes atores sociais, possuindo enfim, uma história única, distinta em relação aos inúmeros Grupos Escolares implantados no país na primeira metade do século 20.

\section{Fontes}

DIÁRIO DO SENADO, 39 $9^{\mathrm{a}}$ Sessão Ordinária do 3. ${ }^{\circ}$ Período da $1 .^{\text {a }}$ legislatura, em 10 de Fevereiro de 1913, pp. 23-35.

JORNAL CIDADE DE CAMPINAS, 13 de outubro de 1910, citado por Souza, 1998, p. 260.

JORNAL DIÁRIO DA CAPITAL, Cuiabá, agosto, 1913.

JORNAL A RAZÃO. Cáceres, 01 de dezembro de 1912.

JORNAL A RAZÃO. Cáceres, 15 de dezembro de 1912.

JORNAL ARGOS. Cáceres, 27 de abril de 1913.

JORNAL A RAZÃO. Cáceres, 31 de agosto de 1913.

JORNAL A RAZÃO. Cáceres, 25 de julho de 1927.

MENSAGENS do Presidente do Estado à Assembléia Legislativa, APMC, 1910-9111912-1915-1916-1919.

RELATÓRIO PRESIDENTE PROVÍNCIA DE MATO GROSSO, 1910. 


\section{Referências}

BITTENCOURT, Circe Maria Fernandes. Repensando o Ensino de História e a criação do fato. São Paulo: Ensino Contexto, 1997.

BOURDIEU, Pierre. "Sobre o poder simbólico". In: BOURDIEU, Pierre. O poder simbólico. Lisboa: DIFEL, 1989, p. 7-15.

CAMARGO, Marilena A. Jorge Guedes de. Coisas Velhas - Um percurso de investigação sobre cultura escolar (1928-1958). São Paulo: Editora UNESP, 2000.

CARVAlHO, José Murilo de. A formação das almas. O imaginário da República no Brasil. São Paulo: Companhia das Letras, 1990.

CARVALHO, Marta Maria Chagas de. A escola e a república. São Paulo: Brasiliense, 1989.

CONTIER, Arnaldo Daraya. Ideologia Dominante em São Paulo através dos Periódicos (1827-1835). São Paulo: Universidade de São Paulo, 1973. (Tese de Doutorado).

CONTIER, A. D. . Imprensa e Ideologia em São Paulo (1822-1842). Matizes do Vocabulário Político e Social. 1. ed. Campinas, SP: Vozes- UNICAMP, 1979.

COSTA, Lucio. Lucio Costa: registro de uma vivência. São Paulo: Empresa das Artes, 1995.

DA MATTA, Roberto. "Você sabe com quem está falando? Um ensaio sobre a distinção entre indivíduo e pessoa no Brasil", in: Carnavais, malandros e heróis. Para uma sociologia do dilema brasileiro. $5^{\text {a }}$ ed., Rio de Janeiro: Guanabara, 1990, p. 146-204 [59p.]

FRAGO, A. V. Del espacio escolar y la escuela como lugar: propuestas y cuestiones. História de la Educacion. Revista Interuniversitaria. Madri,Vol. 12/13. 1993-1994, pp. 17-74.

GIRARDET, Raoul. Em Mitos e mitologias políticas. São Paulo: Cia. das Letras, 1987.

GLÉNISSON, Jean. Iniciação aos Estudos Históricos. Rio de Janeiro: Bertrand, 1991. (Primeira edição 1961).

GRESSLER ,Patrícia. Bonito, cidade das águas: nas trilhas das construções identitárias de Mato Grosso do Sul (1948-2010). 2010. Universidade Federal da Grande Dourados. (Dissertação Mestrado em História).

HOBSBAWM, Eric. Era dos Extremos: breve século XX 1914-1991. São Paulo: Companhia das Letras, 1997.

LEITE, Gervásio. Um século de Instrução Pública. (História do Ensino Primário em Mato Grosso). Goiás: Rio Bonito, 1970.

MENDES, Natalino Ferreira. História de Cáceres - História da administração Municipal. (Tomo I). Cáceres: Secretaria Municipal de Educação, 1973.

NAGLE, Jorge. Educação e Sociedade do Brasil: 1920-29. Araraquara, São Paulo: FFCL, 1996.

NÓVOA, António. A imprensa de Educação e Ensaino: Concepção e organização do repertório português. In: CATANI, Denise e BASTOS, Maria Helena Camara. Educação 
em Revista - A Imprensa Periódica e a história da educação. São Paulo: Editora Escrituras, 1997.

PINSKY, Carla Bassanezi (org). Fontes Históricas. São Paulo: Contexto, 2005.

REIS, Rosinete Maria. "A análise do processo de reconstrução da Escola Pública no Estado de Mato Grosso de 1910 a 1927”, Revista HISTEDBR on-line, Campinas, n.21, p. 44-51, 2006.

RODRIGUES, José Honório. Teoria da História do Brasil: Introdução Metodológica. Vol.1. 2.ed. São Paulo: Companhia Editora Nacional, 1957. (Primeira edição: 1949).

SILVA, Adriane Cristine. Grupo Esperidião Marques: Uma contribuição para os estudos das Instituições Escolares em Mato Grosso 1910-1947. Dourados, MS: UFGD, 2011, $183 f$. (Dissertação de Mestrado)

SOUZA, Rosa Fátima de. Templos de espetáculos e ritos. In: SOUZA, Rosa Fátima de. Templos de civilização: a implantação da escola primária graduada no Estado de São Paulo (1890-1910). São Paulo: EdUNESP, 1998. pp 241-278.

SOUZA, Rosa Fátima de. Espaço da educação e da civilização: origens dos grupos escolares no Brasil. In: SAVIANI, Dermeval. O legado educacional do século XIX. Campinas, SP: Autores Associados, 2006.

VIDAL. Diana G. Culturas escolares: estudo sobre práticas de leitura e escrita na escola pública primária - Brasil e França, final do século XIX. 2004. Tese (Livre Docência)- Faculdade de Educação da Universidade de São Paulo, São Paulo, 2004.

Notas:

${ }^{1}$ Maria do Carmo Brazil: mc.2708@hotmail.com; e Adriane Cristine Silva: nanecristines@ hotmail.com.

${ }^{2}$ Cáceres, cidade colonial de Mato Grosso, localiza-se à margem direita do rio Paraguai e foi fundada em 06 de outubro de 1778, por ordem do $4^{\circ}$ Capitão General Luiz de Albuquerque de Melo Pereira e Cáceres, como objetivo estratégico de promover a ocupação, o povoamento e garantir a posse lusa no extremo oeste brasileiro.

Recebido em: $\quad$ 05/01/12

Aprovado em: $\quad 16 / 02 / 12$ 